\title{
Investigating the Market Strategy of Smart food's latest product based on Business Analysis Models
}

\author{
Baoyi Jiang \\ The International Department, The Affiliated High School of Guangzhou University, Guangzhou, Guangdong 510000, \\ China \\ *mable4320@qq.com
}

\begin{abstract}
The purpose of this paper is to evaluate the profitability potential for a new low-carbohydrate snack and predict its future market condition. By applying the PEST model, Porter's five forces model, and SWOT model, I analyzed the market condition from both external and internal factors that would impact the market of K-Pack, including the competition within the snacking industry, the strengthens and weaknesses of the firm, etc. Results show that the future market of the product labeled as K-Pack shows a positive tendency, and they are likely to make sizable profits if they enter the market soon. My paper shows the broad applicability of these three models and their effectiveness when taking into use.
\end{abstract}

Keywords: PEST analysis, Porter's Five forces analysis, SWOT analysis.

\section{INTRODUCTION}

Healthy food is crucial to lots of citizens during their daily life and work. Rising demand for foods that fulfill health needs, environmentally friendly, convenience driving innovations and developments in the current snacking industry. To keep pace with these fluctuations, snack manufacturers must alter their offerings to fit the public's tastes. Within just a few years after nutritionists advocated the significance of health as well as eating habits, gradually, low-carbohydrate food was confirmed to be one of the top priority options in the snack category. It was found that the association between competencies and business success was more strongly evident in hostile and dynamic environments than in the more benign and stable environment. Taking the global market scale into consideration. With the growing attention on body health, individuals favor these lowcarbohydrate snacks because they accommodate people with a healthier diet, increase their nutrients intake while satisfying their appetite.

To a certain degree, no negligible, the society stands to benefit from the positive externality of preferring low-carbohydrates as the partiality toward the new kind of snack will progressively alleviate the obesity rate as many countries are trying their best to changing the nutrition environment by supporting healthy eating. As the shift in consumer preferences has had direct influences on the innovation within the snack market, the Smartfood company decided to sell a snack that caters to the public needs and is also low-carbohydrate and portable, which matches the market need. The product is tentatively labeled as K-Pack and is packaged to look like a typical candy bar.

Currently, the Smartfood company faces many difficulties as the snacking industry is changing every moment. As a new product, K-Pack may have weak consumer loyalty even though the smart food company has already buildup its brand reputation. Moreover, since all product-markets including the snack market, is coming up with new ideas every day, the rapid technological innovations and new ingredients can be great substitutes to the K-Pack. Thus, the company should formulate strategies to obtain competitiveness and promote its sales within the industry. It attracts great attention to these companies' decision-makers to consider how this product would become popular in the market. Lots of analyses need to be conducted.

There are diverse models to investigate and forecast the business developments of the companies to help them make appropriate marketing tactics. PEST model is a powerful and widely used tool for companies to 
understand the risk of their planned strategy. Carruthers [4] found that the acronym PEST aims to make us look at political, economic, social, and technological pressures for change when assessing the business environment. Sammut-Bonnici and Galea claimed [5] that PEST analysis identifies the changes and the effects of the external macro-environment on a firm's competitive position. Zhu et al.[6] used the PEST model to explore the development modes of China's bioenergy industry. In this research paper, I also used the PEST model to analyze the future market of K-Pack.

SWOT has been used extensively by marketing directors in business settings to uncover new outlooks and identify problems that will impede progress. Miller [7] used the SWOT analysis model to discuss the strengths, weaknesses, opportunities, and threats that are apparent to an investigator if they venture into applying metabolomics to environmental exposures. Namugenyi et al. [8] and his mates designed a new SWOT model to oversee new insights of various business contexts that can guide SWOT analyzers and provide digital ecosystem services in multiple industry operations in an optimum manner. By comparing results from the SWOT analysis, Van Wijngaarden [9] analyzed different parts of the health care sector in the Netherlands and made his conclusions. By using SWOT analysis, in this paper, I successfully forecast the future market condition for $\mathrm{K}$ Pack.

Porter's five forces model has been one of the most influential models within business schools and among managers. Indiatsy et al. [10] used Porter's Five forces model to investigate Kenyan Banking which industry in the rapidly changing environment. Yunna and Yisheng [11] applied the Five forces model to insight into the competitive landscape of the shale gas market and gained a view into the situation of the shale gas industry. In the article of Wellner and Lakotta [12], they investigated the profitability potential of the German railway industry based on Porter's Five Forces, which considers different former empirical expansion proposals.

In this paper, by using three models to investigate the current market for K-Pack, which are PEST, Porter's Five Forces, and SWOT analysis. According to the PEST model, I can draw the results that the consumer group's preferences and diversities, along with the government's support provide the product with more chances to sell. Furthermore, with the growing attention on eating a healthy snack, K-Pack can cater to the public needs as it is low-carbohydrate. Using the porter's five forces model, I can conclude that as K-Pack is highquality and wholesome, the new entrants in snack industry are less likely to impact it and thus allow the company to dominant the snack market. In the SWOT model, the strengthens include that robust financial support and strong advertising tactics accompany by the novelty of K-Pack allow the company to dominate the market. However, its weaknesses are that other snack products can be strong substitutes and may collusive against K-Pack. Based on the scrutiny above, I propose that the company is going overcomes the risk to sell new products and dominate the market.

The remainder of the paper is organized as follows: Section 2 is the background description of the K-Pack and the company; Section 3 illustrates the general concept of the business model I used in this paper; Section 4 shows the detailed and resultant analyses of the product. The last section presents my conclusion on K-Pack.

\section{BACKGROUND DESCRIPTION}

In this paper, I aim at the determinants that impact the sales of the products in the Smartfood company, for example, conducting relevant research. A snack/diet food company is considering adding a new food product tentatively labeled as K-Pack to their existing product line. Meanwhile, they are currently concerned about whether the product will be bestselling and have little competition in the diet-snack food category if they enter the market in two years. As most of the snack products in the snack market have short life cycles and K-Pack prone to stand out for its novelty and ability to achieve people's needs more healthily. The Smartfood company determines to subcontract the production and the distribution of K-Pack to other companies to lower the input cost. Simultaneously, the predicted total annual cost to contract the production and distribution is expected to change very little within several years. To guarantee that the prediction of the product is credible, the company director designs to conduct the following test to ensure it is worth putting into efforts. They implement a four-month test market study at 24 grocery stores in 4 different cities and use a "controlled" introduction of K-Pack to achieve their goal:

(1) Better estimations of the sales for the first year.

(2) The effects of the chosen marketing mix on sales.

(3) The profit potential for K-Pack.

In this case, price (50 cents, 60 cents, 70 cents), advertising (a simulation of a $\$ 3$ million introduction plan and a $\$ 3.5$ one), and location of K-pack within each store (L1: bakery section versus L2: breakfast section) are considered for final marketing mix. The author is using different prices and the same advertising strategies in the same cities or the same prices and different advertising in different cities to control the study variables. 


\section{BUSINESS METHOD}

In this specific section, to predict the future market of the K-Pack, I introduce the following models to verify and evaluate the significance of the decision to enter the market.

\subsection{PEST Analysis}

PEST Analysis (Political, Environmental, Social, Technological) is a business method whereby a company can assess most of the major external factors that affect its operation and thus become more competitive in the product market. PEST Analysis helps organizations capitalizing on opportunities offered by existing conditions in the circumstance. Furthermore, it can also identify current or possible future challenges, allowing effective tactics of how to best manage these challenges. It is believed that Harvard professor Francis J. Aguilar first introduced the PEST Analysis. In his 1967 publication "Scanning the Business Environment," professor Aguilar contended that this analytic model helps firms to be forewarned of and better prepared for imminent changes, thereby allowing the corporation to stay ahead of competitors.

\subsection{Porter's Five Forces Analysis}

Porter's Five Forces is a model which analyzes five competitive forces that shape every industry and aid determine an industry's weaknesses and strengths. With the help of this model, firms can better identify the industry's structure to conclude their corporate strategy. The model is applied to any segment of the economy to understand the competition within the industry, enhancing the firm's long-term profitability. The model named after Harvard Business School professor Micheal E. Porter, who recognized that corporations prefer to keep their concerns on their rivals. It encourages firms to look beyond the actions of their competitors and evaluate other factors that could have impacts on the product environment. Notably, Porter stated that Porter's Five Forces mainly focus on parts that are permanently affecting the industry instead of those temporary factors.

\subsection{SWOT Analysis}

SWOT (Strengths, Weaknesses, Opportunities, and Threats) analysis is a framework used to evaluate a company's competitive position and to develop corresponding strategies. In 1982, Dr. Heinz Weihrich proposed the use of a $2 \times 2$ matrix for carrying out SWOT analysis. By analyzing the internal and external factors, including current and future potential outcomes, it is now widely used in the areas of strategical planning. Notably, swot analysis is not limited to companies. Individuals are also able to use this model to engage in constructive introspection and form personal improvement goals.

\section{RESULT ANALYSES}

In this case, I use the PEST model, Porter's Five Forces model, and SWOT model to better predict the market condition of K-Pack.

\subsection{PEST Analysis}

In the PEST analysis, I scrutinize the political, economic, social, and technological factors to gain findings. The political factors illustrate the extent to which the adopted policies of the government and geopolitical uncertainties on the K-Pack market. The economic aspect determines the impact of economic power such as population growth, income level, consumption preference on the market. The social factors indicate that the influence of education level, religion, values on the snack market. The technological aspect demonstrates the impact of Internet connectivity and automation.

\section{(1) Political factors}

The government supports snack businesses to invent healthier products. Snacks in the same category like KPack provide people with well-being as the government has announced that healthier food is salutary to human health. Through supporting and subsiding businesses that produce health snacks, the government can gradually minimalize the intense problems caused by the obesity of its people.

Vast consumers group provides audiences for smartfood to sell its products. The products are planned to sell worldwide as the smartfood company has good international relations. The potential consumer groups are so huge that different ethnic groups who have diverse tastes and preferences will increase the number of buyers of K-Pack.

\section{(2) Economic factors}

The supply of K-Pack is strong as the smartfood company wanted to increase sales. By ensuring the supply of K-Pack, consumer countries of K-Pack probably have higher income and prefer nutritious snacks. With the solid economic strength of consumer countries, mainly developed countries, they have a relatively higher average income level among all nations, and healthy snack food is in the category of normal good. Hence, most people have exceeded the level of concern about having ample food\&cloth and start to attach importance to their eating diet. Paying more attention to healthy eating habits means to value more about the intake which increasing the demand of the KPack market and guarantee its competitiveness.

The US dollar probably continues to depreciate due to the coronavirus and will positively affect the product market of K-Pack. The pandemic broke out, which affected the global market as the dollar depreciated and 
will increase the export of domestic products while decreasing the number of imported products. Depreciation of the dollar will lead to less import which assuages the competitiveness of the domestic market and benefits the sale volume of K-Pack.

Quarantine last year enlightened the significance of eating healthy food to all citizens in the world. It influences the way people consider eating healthily and would increase the sales of K-Pack as people have to stay at home and focus more on their health than before. The quarantine enables people to realize the benefits of eating K-Pack because it is convenient and lowcarbohydrates.

\section{(3) Social factors}

Young people prefer eating snacks which increase the sales of K-Pack. The global population keeps increasing as many countries are taking action to increase the infant birth rate. Large numbers of youngsters who bias snacks would only choose K-Pack, for the health and joy it provides if the product dominants the market.

Increased education level results in the consciousness of health needs. With the accelerating attention to health in western countries, as people have been educated to realize the essence of well-being, the market for K-Pack opened to make a change in daily lives.

\section{(4) Technological factors}

Government subsidy to technology improvement benefits the production of K-Pack. As a free-rider of improving techniques, the input cost to produce K-Pack may be lower and benefits the company by providing more profits.

Competitors may use the same ingredients as $\mathrm{K}$ Pack, which hurts the profit of smartfood. Many technological competitors of K-Pack can duplicate its ingredient method on the Internet if smartfood cannot apply for a patent rapidly. Thus, some of the techniques would be imitated and reproduced.

\subsection{Porter's Five Forces Analysis}

Porter's Five Forces model includes the impacts of rivalry within the snack industry, the bargaining power of suppliers and buyers, the threat of new entrants and substitute products.

(1) The intensity of rivalry in the industry

As a new product, K-Pack is a rival in the snacks industry, producing high-quality and wholesome products. Therefore, smartfood can maintain its position in the snack industry.

Firms in the snack food industry have diverse goals and distinct approaches to competing in the market.
Obviously, they tend to lack similarity to better stand out in the market and attract consumers. Therefore, if $\mathrm{K}$ Pack is unique and novel enough, the smartfood company is prone to dominate the market.

\section{(2) Increased bargaining power of suppliers}

Increasing the bargaining power of suppliers means increasing the price of input factors and reducing the quality of unit value, which hurts the profits of smartfood. This is a significant variable in business as numerous suppliers, and potential suppliers limit the bargaining power of K-Pack.

(3) Increased bargaining power of buyers

Only when the product is in the monopsonistic market as the customer base is low will the bargaining power of buyers be crucial. However, since the consumer groups of K-Pack are huge and uneasy about being affected, the smartfood company is less likely to lose profit in this aspect.

(4) The threat of new entrants

New entrants bring new production capacity and resources at the same time but may compete with existing companies like smartfood and eventually lower the existing corporate profits in the industry. Actually, the threat dependent on the size of the new entrants. If the number of new entrants is small, they won't greatly affect the market. Once the smartfood company can monopoly the market of a healthy snack, the threats made by the new entrants will be minimized.

(5) The threat of substitute products

If the substitutes have a lower price, better quality, and lower switching cost, the stronger the competitive pressure will occur. For instance, a company that produces a new type of health snack called "kind" became a giant in the healthy snacks industry. Only if smartfood company can enter the market with novelty and hold their position can they make a great success.

\subsection{SWOT Analysis}

The SWOT model is an organized list that aims to identify K-Pack's strengths, weaknesses, opportunities, and threats. The following Table identifies these four areas. 
Table 1. SWOT analysis results

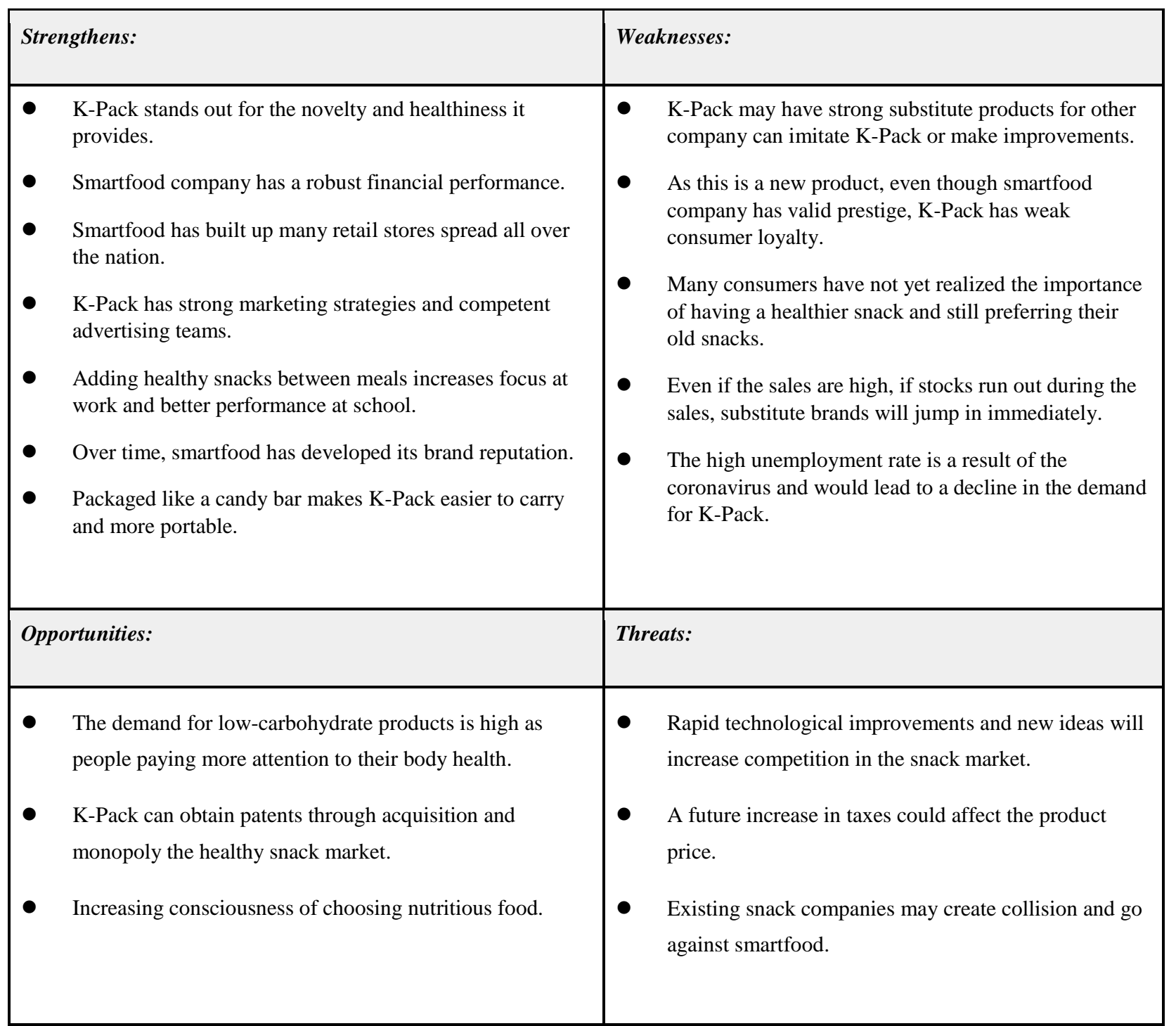

By interpreting the above models, I can conclude that the future market of K-Pack prone to be positive as the government tends to support this type of business while the long-term audiences are diverse and the demand for K-Pack is steadily increasing. If smartfood can enter the market soon and maintain its position, I assert that the K-Pack will be dominating the snack market.

\section{CONCLUSION}

In this paper, I research mainly on the future snack market condition and the market competitiveness of $\mathrm{K}$ Pack by identifying the PEST, Porter's Five Forces, and SWOT analysis. Based on the scrutiny of these three models, I summarize the dominant drivers that influence the sales of K-Pack in the snack industry and the current shortages of the smartfood company.

Based on the PEST model, by considering factors from political, economic, social, technological aspects, I conclude that the future market trend for K-Pack is positive. By gaining strong government support for healthy snack food along with the education of rising awareness of valuing health people had during the epidemic, thereby increasing the sales of K-Pack. The outbreak of the coronavirus stymied the economic development. Admitted, on the other hand, it lowers the price level in the product market, stimulates citizens to prefer the domestic snack market, and contributes to the profit of K-Pack.

By investigating Porter's Five Forces model, the smartfood company is still able to show the tendency of dominating the market and make a sizable revenue. Considering the rivalry within the industry, the bargaining power, and the threat of competitors, I find that as the consumer base of K-Pack is large enough which provides various tastes and preference to increase the sales of K-Pack. Similar firms in snack industry have different goals which diminish the fierce competitions, new entrants in the market won't be able 
to affect the market for their threats are highly depend on their firm sizes.

Finally, by interpreting the SWOT model, the finding reveals that K-Pack stands out for its novelty and valid reputation within the industry, accompanied by strong marketing tactics, robust financial support, and long-term supply. In addition, with the help from the increasing consciousness of eating healthily, the demand curve of K-Pack is relatively inelastic and is conducive to the sales of K-Pack.

On the contrary, by analyzing these models, I notice that the smartfood company still has several obstacles to overcome if they want to be more competitive in the snack market. The consumer loyalty of this new product is weak no matter how valid its brand prestige is. As the pandemic is damaging to all product markets and many people, many lose their jobs during the quarantine, increasing the unemployment rate causing citizens to reduce their consumption. Hence, the demand curve of all snack food, including K-Pack, is unstable. If smartfood companies can make great use of this condition, they may control the market; however, once they lose the opportunity to dominate the market, they would be severely affected. To minimize these impacts, the smartfood company should gradually diversify the forms of publicity based on the existing single advertising model and take more time to consider the impacts from other independent variables.

\section{REFERENCES}

[1] Carruthers, H. (2009). Using PEST analysis to improve business performance. In practice, 31(1), 37-39.

[2] Sammut - Bonnici, T., \& Galea, D. (2015). PEST analysis. Wiley Encyclopedia of management, 1-1.

[3] C. Baier, J-P. Katoen, Principles of Model Checking, MIT Press, 2008.
[4] Zhu, L., Hiltunen, E., Antila, E., Huang, F., \& Song, L. (2015). Investigation of China's bioenergy industry development modes based on a SWOT - PEST model. International Journal of Sustainable Energy, 34(8), 552-559.

[5] Miller, M. G. (2007). Environmental metabolomics: a SWOT analysis (strengths, weaknesses, opportunities, and threats). Journal of proteome research, 6(2), 540-545.

[8] Namugenyi, C., Nimmagadda, S. L., \& Reiners, T. (2019). Design of a SWOT analysis model and its evaluation in diverse digital business ecosystem contexts. Procedia Computer Science, 159, 1145 1154.

[9] Van Wijngaarden, J. D., Scholten, G. R., \& Van Wijk, K. P. (2012). Strategic analysis for health care organizations: the suitability of the SWOT analysis. The International Journal of health planning and management, 27(1), 34-49.

[10] Indiatsy, C. M., Mucheru, S. M., Mandere, E. N., Bichanga, J. M., \& Gongera, E. G. (2014). The application of Porter's five forces model on organization performance: A case of cooperative bank of Kenya Ltd.

[11] Yunna, W., \& Yisheng, Y. (2014). The competition situation analysis of shale gas industry in China: Applying Porter's five forces and scenario model. Renewable and Sustainable Energy Reviews, 40, 798-805.

[12] Wellner, S., \& Lakotta, J. (2020). Porter's Five Forces in the German railway industry. Journal of Rail Transport Planning \& Management, 14, 100181. 